\title{
Current Use of the Artificial Urinary Sphincter in Adult Females
}

\author{
Benoit Peyronnet ${ }^{1,2}$ (D) $\cdot$ Tamsin Greenwell $^{3} \cdot$ Gary Gray $^{4} \cdot$ Rose Khavari $^{5} \cdot$ Nikesh Thiruchelvam $^{6} \cdot$ Grégoire Capon $^{7}$. \\ Jeremy Ockrim ${ }^{3}$. Luis Lopez-Fando ${ }^{8}$. Jason Gilleran ${ }^{9} \cdot$ Georges Fournier $^{10} \cdot$ Gommert A. Van Koeveringe $^{11}$. \\ Frank Van Der Aa ${ }^{12}$
}

Accepted: 15 October 2020

(C) Springer Science+Business Media, LLC, part of Springer Nature 2020

\begin{abstract}
Purpose of Review The aim of the present report was to review the recent evidences regarding the use of artificial urinary sphincter (AUS) in adult females.

Recent Findings While the excellent functional outcomes of AUS in female patients with stress urinary incontinence (SUI) due to intrinsic sphincter deficiency (ISD) have been reported for decades, its use has remained confidential in most countries likely due to its challenging implantation and inherent morbidity. Over the past few years, laparoscopic and, more recently, robotic techniques of AUS implantation in female patients have been described with promising perioperative outcomes. As a result, the use of AUS has increased in several countries. The indications are mostly recurrent or persistent SUI after previous antiincontinence procedures and neurogenic SUI. Owing to its unique potential to restore continence while maintaining low outlet resistance during the voiding phase, AUS may be of special interest in female patients with detrusor underactivity. High level of evidence data from trials which are underway, along with developments in robotic surgery and technological refinements of the device, may well, almost 50 years after its introduction, give to the AUS its momentum as a major contributor in the female SUI armamentarium.

Summary While the use of AUS in female patients has been restricted to some countries and a few high-volume centers, it has started spreading again over the past few years, thanks to the rise of minimally invasive approaches which facilitate its implantation, and this is yielding promising outcomes.
\end{abstract}

Keywords (MeSH) Urinary sphincter, artificial $\cdot$ Female $\cdot$ Urinary incontinence, stress $\cdot$ Robotics

\section{Introduction}

Stress urinary incontinence (SUI) is a highly prevalent symptom in women which occurrence increases with age [1]. The

This article is part of the Topical Collection on Female Urology

Benoit Peyronnet

peyronnetbenoit@hotmail.fr

1 Department of Urology, University of Rennes, Rennes, France

2 Service d'Urologie, Hopital Pontchaillou, 2 rue Henri Le Guilloux, 35000 Rennes, France

3 Department of Urology, University College London Hospital, London, UK

4 Department of Urology, University of Alberta, Edmonton, Canada

5 Department of Urology, Houston Methodist Hospital, Houston, TX, USA negative impact of SUI on the quality of life (qol) is the main reason for patients to seek surgical treatment [2] and is largely influenced by incontinence severity and prior antiincontinence procedures [3]. While the impact of the current
6 Department of Urology, Addenbrooke's Hospital, Cambridge, UK

7 Department of Urology, University of Bordeaux, Bordeaux, France

8 Department of Urology, University Hospital Ramon y Cajal, Madrid, Spain

9 Department of Urology, William Beaumont Hospital, Royal Oak, MI, USA

10 Department of Urology, University of Brest, Brest, France

11 Department of Urology, Maastricht University Medical Centre, Maastricht, Netherlands

12 University Hospitals, KU Leuven, Leuven, Belgium 
mesh controversy on future SUI surgical treatment algorithms remains uncertain, synthetic midurethral sling (MUS) are still widely regarded as the gold standard treatment for most women with SUI [4*•] especially those with urethral hypermobility $[4 \bullet \bullet, 5]$. The surgical management is less consensual in female patients with a SUI related to intrinsic sphincter deficiency (ISD), i.e., patients who have failed previous antiincontinence surgical procedures or patients with neurogenic SUI [6]. Although fascial pubovaginal slings (FPVS), bulking agents, and repeat MUS are the favored options in most countries $[7,8]$, some use the artificial urinary sphincter (AUS) AMS 800 (Boston Scientific ${ }^{\mathrm{TM}}$; Inc. USA) in these scenarios [9]. The aim of the present manuscript was to provide an overview on the current use of AUS in adult females.

\section{Methods}

A literature search was conducted in January 2020 using the MedLine and Embase databases, screening for randomized controlled trials (RCTs), prospective and retrospective series, and reviews on female AUS. The search strategy involved a free text protocol with the following keywords ("artificial urinary sphincter" or "artificial sphincter") AND ("female" or "women") that were used alone or in combination. Only articles published in English and deemed relevant were included in this review.

\section{The Origins}

Nowadays, the AUS is predominantly used in male patients with post-prostatectomy incontinence [10]. Yet, most people ignore this, but the American Medical System AUS was initially designed mostly for women [11]. Indeed, the first clinical experiences with AUS date back from the early 1970s [11, 12], before the spread of radical prostatectomy and therefore in an era with a very low prevalence of male SUI, mainly restricted to neurogenic patients. In the first reports published, the AUS cuff was implanted at the bladder neck level using an abdominal approach [11]. Several small sample size series were then reported in the 1980s and 1990s, mostly from North American institutions without real take off in the use of AUS in female patients. Some of these series reported the use of a vaginal approach which was promptly abandoned by a vast majority of surgeons, likely due to poor outcomes although it could not be asserted because very scarce series were published [13••]. In the mid-1990s, female AUS was not approved by the US Food and Drug Administration (FDA) and from then was almost abandoned by US urologists [10]. Over the past two decades, female AUS was used mostly in Europe, especially in France and in some tertiary referral centers in the UK, Belgium, the Netherlands, and Germany [14] using an open approach with a recent rise of minimally invasive approaches which helped to overcome the technical complexity

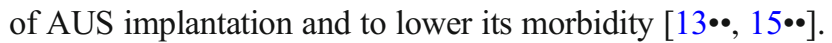

\section{Consideration on Indications}

Stress urinary incontinence (SUI) is common in women and increases with age with a reported prevalence of up to $30-60 \%$ in elderly women [16]. Over the past two decades, the use of synthetic midurethral slings (MUS) has become the gold standard surgical treatment of SUI in female patients [4••, 16]. Beyond the current mesh controversy that is challenging this paradigm in numerous parts of the world [17], one should note that MUS fail in about $15 \%$ of women with SUI [18] and longterm recurrence of SUI as high as $68.3 \%$ have been reported [19]. Female patients with a lack of urethral mobility $[9,20]$ and, to a lesser extent, those with low urethral closure pressure have an increased risk of persistent SUI after MUS, as high as $75 \%[9,21]$.

The mechanism causing SUI in these patients is often termed intrinsic sphincter deficiency (ISD) and refers to the incomplete coaptation of the urethral lumen due to decreased outlet resistance as opposed to SUI related to urethral hypermobility referring to lack of urethral support $[1,9]$. There is no universally accepted definition of SUI due to ISD $[1,9]$. The ISD definition used in France is a combination of clinical and urodynamic criteria, the former being the key determinant: demonstrable SUI on cough stress test with lack of urethral mobility, negative Marshall/Bonney test (i.e., still leaking on cough stress test despite urethral support), and a low maximum urethral closure pressure [9]. Fixed urethra is the core feature of this definition which makes the indication of female AUS highly dependent on clinical judgment and expertise as standardized measurements of urethral mobility such as the Qtip test or urethral ultrasound have not been widely adopted for various reasons [22, 23]. However, visual urethral mobility evaluation, when performed by experienced clinicians, has been reported to strongly correlate with the Q-tip test [24]. Other clinical criteria such as failure of a first antiincontinence procedure, high SUI scores, constant leakage for any daily activity, and leakage with abdominal straining may reinforce the clinical suspicion of ISD [9]. In female patients with SUI due to ISD, as defined above, AUS is recommended as the gold standard treatment in the French guidelines [9]. In daily practice, SUI due to ISD most commonly occurs in two different populations: female patients with neurogenic stress urinary incontinence (usually due to spinal cord injury (SCI), spina bifida, cauda equina syndrome or pelvic trauma), or patients who failed previous anti-incontinence surgical procedures $[15 \bullet \bullet$. However, there are considerable discrepancies in the role and use of AUS in female patients from one country to another and the situation in France has for long 
been pretty unique with a much wider use than in any other country in the world $[25,26 \bullet \bullet$.

Beyond the excellent functional outcomes reported in the literature (see below), the main theoretical advantage of AUS over other surgical options for female SUI due to ISD is that it would be the only anti-incontinence procedure with the ability to restore both normal storage and voiding function by increasing the outlet resistance at rest when the cuff is closed but maintaining low outlet resistance during the voiding phase with the cuff being opened [13••]. Despite the fact that urodynamic data are lacking to demonstrate this hypothesis, the mechanisms of action of all the other anti-incontinence procedures traditionally used in female patients with SUI due to ISD (i.e., bulking agents, fascial slings, adjustable MUS) have been shown to rely on bladder outlet obstruction [27]. AUS could then be of particular interest in the subgroup of female patients with SUI and coexistent detrusor underactivity.

With regard to the neurogenic SUI population, a few longterm series have suggested satisfactory functional outcomes with relatively limited rates of erosion and infection [28••, 29]. However, AUS in neurologic patients may have two significant drawbacks. Firstly, myelomeningocele and SCI are younger patient populations and AUS implantation would expose these patients to multiple reoperations for surgical revision over their lifetime. Secondly, the AUS asset of being hypothetically non-obstructive is of no interest in this selfcatheterizing population, with, conversely, a possibly increased risk of urinary tract erosion due to clean-intermittent catheterization and an increased risk of exposition due to the neurological perineal impairment and wheelchair use [30].

The total absence of comparative data in the literature between AUS and fascial sling or any other anti-incontinence procedures makes it impossible to draw robust conclusions as to where AUS might be placed in the surgical armamentarium for recurrent/persistent SUI and neurogenic SUI in female patients and more globally to build an evidenced-based therapeutic algorithm in these patients' population [31, 32].

\section{Current Role of Female AUS According to National and International Guidelines}

According to the European Association of Urology guidelines, AUS should be implanted only as a last resort procedure and only in expert centers, the panel recommending consideration of synthetic sling, colposuspension, and autologous sling as first options in these patients and to inform them of the high risk of complications; mechanical failure, or need for explantation (level of evidence 3, grade of recommendations: weak) [33]. The International Consultation on Incontinence (ICI) of the International Continence Society (ICS) recommends use of AUS only in highly selected individuals, usually those with recurrent SUI and only with appropriate counseling regarding the likely need for revision over time and the lack of long-term RCT data (grade C recommendation) [34]. The NICE guidelines recommend against AUS as an option to manage female SUI unless previous surgery have failed [35]. A counterargument to placing female AUS very late in the armamentarium would be that the risk of surgical complications may increase proportionally to the number of previous anti-incontinence procedures [36••]. Because AUS in female patients is not approved by the Food and Drugs Administration (FDA), it is not mentioned as an option in the American Urological Association (AUA) guidelines on SUI [37] and its use has been very limited in the United States of America (USA) over the past years [10]. In contrast with all these international guidelines, the French national guidelines recommend AUS as the gold standard treatment of female patients with ISD-related SUI [9]. The indications of AUS in female patients in various national and international guidelines and in high-volume implanting centers are summarized in Table 1.

\section{Preoperative Work-Up}

The preoperative work-up usually performed before female robotic AUS implantation is summarized in Table 2. It includes a thorough medical history, paying special attention to history of previous anti-incontinence surgery, and more globally of previous pelvic surgery. Many of the female AUS patients have undergone previous midurethral slings and the question of excision of the tape before scheduling the AUS implantation should always be raised, especially in those with voiding dysfunction or other mesh-related complications. History of pelvic radiation therapy should also be sought because it has been proven to increase the risk of AUS erosion in female patients in open series [36] and is traditionally regarded as a contraindication to AUS implantation in female patients. During the clinical interview, subclinical cognitive dysfunction should be sought, especially in elderly women as it may hinder device handling [13••]. Physical examination should investigate whether the patient will be able to easily manipulate the device, especially in women, making sure they can grab their labia majora which can be challenging in obese patients. A pencil test may be useful to assess patients' cognitive function and manual dexterity. The principle of the pencil test is to ask the patient to plug in and remove a pen cap. Physical examination will also strive to demonstrate SUI using a cough stress test in the lithotomy position. In female patients, the urethral mobility should be assessed and an Ulmsten test may be performed, evaluating whether SUI is corrected when supporting the mid urethra. When urine leakage is not demonstrated with the patient lying, having the patient cough while standing may help unmask 
Table 1 Indications of female artificial urinary sphincter in current guidelines

\begin{tabular}{|c|c|c|}
\hline & $\begin{array}{l}\text { Indications of female } \\
\text { artificial urinary sphincter }\end{array}$ & $\begin{array}{l}\text { Grade of } \\
\text { recommendations/ } \\
\text { level of evidence }\end{array}$ \\
\hline $\begin{array}{l}\text { European Association } \\
\text { of Urology (EAU) } \\
{[32]}\end{array}$ & $\begin{array}{l}\text { Complicated stress } \\
\text { urinary incontinence, } \\
\text { as a last resort option, } \\
\text { only in expert centers }\end{array}$ & $\begin{array}{l}\text { Level of evidence: } \\
\text { 3/grade of rec- } \\
\text { ommendations: } \\
\text { weak }\end{array}$ \\
\hline $\begin{array}{l}\text { International } \\
\text { Consultation on } \\
\text { Incontinence } \\
\text { (ICI/ICS) [33] }\end{array}$ & $\begin{array}{l}\text { In highly selected } \\
\text { individuals, usually } \\
\text { those with recurrent } \\
\text { SUI }\end{array}$ & $\begin{array}{l}\text { Grade of } \\
\text { recommenda- } \\
\text { tions: C }\end{array}$ \\
\hline $\begin{array}{l}\text { American Urological } \\
\text { Association (AUA) } \\
{[36]}\end{array}$ & Not mentioned & NA \\
\hline $\begin{array}{l}\text { National Institute for } \\
\text { Health and Care } \\
\text { Excellence (NICE) } \\
\text { [34] }\end{array}$ & $\begin{array}{l}\text { Only in case of failed } \\
\text { previous surgeries }\end{array}$ & NR \\
\hline $\begin{array}{l}\text { French Association of } \\
\text { Urology } \\
\text { (AFU) [9] }\end{array}$ & $\begin{array}{l}\text { Gold standard treatment } \\
\text { for SUI due to ISD, } \\
\text { especially if lack of } \\
\text { urethral mobility }\end{array}$ & NR \\
\hline $\begin{array}{c}\text { Canadian guidelines } \\
\text { of Urology [37] }\end{array}$ & $\begin{array}{l}\text { One of the options if ISD } \\
\text { is the primary cause of } \\
\text { SUI }\end{array}$ & $\begin{array}{l}\text { Grade of } \\
\text { recommenda- } \\
\text { tions: B }\end{array}$ \\
\hline $\begin{array}{l}\text { High-volume } \\
\text { implanting centers } \\
\text { in Europe }\end{array}$ & $\begin{array}{l}\text { Recurrent or persistent } \\
\text { SUI after one or } \\
\text { multiple previous } \\
\text { anti-incontinence pro- } \\
\text { cedures } \\
\text { Neurogenic SUI }\end{array}$ & NR \\
\hline
\end{tabular}

$I S D$ intrinsic sphincter deficiency

$S U I$ stress urinary incontinence

$N R$ not reported

NA not applicable

SUI. Pelvic organ prolapse is also sought and, when present, can lead to offer concomitant sacrocolpopexy [15••]. In case vulvovaginal atrophy is noted, topical estrogen therapy preoperatively can be prescribed aiming to minimize the risk of intraoperative vaginal injury although there is currently no

Table 2 Usual preoperative work-up prior to AUS implantation

Female AUS preoperative work-up
Thorough medical history
Physical examination
Pencil test
Questionnaires (e.g., ICIQ-SF,UDI)
Uroflowmetry and post-void residual
(except in self-catheterizing neurogenic
patients)
Urethrocystoscopy
Urodynamics

data to support this idea. Validated self-administered questionnaires are done to further explore and gauge lower urinary tract symptoms (LUTS) as well as their impact on patients' quality of life. A free uroflowmetry and post-void residual (PVR) can be useful to rule out voiding dysfunction which could prompt to perform midurethral slings excision/ urethrolysis before scheduling the AUS implantation. A urethrocystoscopy is also part of the systematic preoperative work-up to rule out midurethral sling perforation and bladder stone. Finally, urodynamics is routinely done preoperatively and of particular importance in neurological patients to detect detrusor overactivity (DO) or poor compliance bladder that could worsen and result in upper urinary tract deterioration post-operatively. In non-neurogenic patients with constant leakage, defunctionalized bladder can mimic DO and poor compliance and is, therefore, rarely changing the indication [38]. Urodynamics could also be useful to measure maximum urethral closure pressure and/or Valsalva leak point pressure which reductions reinforce the suspicion of ISD [1, 9]. Videourodynamics might have the added value over standard urodynamic to assess the bladder neck and urethra mobility thanks to the fluoroscopic images $[1,9]$.

\section{Traditional Open Surgical Technique}

The principle of female AUS implantation is to insert the exact same three components AMS- 800 device that is used in male patients placing the cuff around the bladder neck, the pressureregulating balloon $(\mathrm{PRB})$ in the subperitoneal space, and the pump in the labia majora. Although the vaginal approach has been used initially in the 1980s, it has been largely abandoned in favor of an abdominal approach. Antibiotic prophylaxis is given and a 14 Fr indwelling catheter is inserted. In the traditional open approach technique, the bladder is dropped down from the abdominal wall and the Retzius space is dissected downwards until the endopelvic fascia is identified on both sides of the bladder neck [36••]. The surgeon then places one finger in one of the vaginal fornixes pushing upward and laterally to put the vaginal wall on tension and facilitate the identification of the vesicovaginal plane, historically called the bald plane (because white, shiny and smooth looking like a bald head), by dissecting on the tip of the finger with cold scissor [36••]. Once the vesicovaginal plane has been found, the surgeon dissects the posterior part of the bladder neck with the scissor along his finger. The same maneuver is done on the other side of the bladder neck, and the two dissected spaces are joined together to place the measuring tape all around the bladder neck. The cuff is then inserted as well as the balloon (a $61-70 \mathrm{cmH} 2 \mathrm{O} \mathrm{PRB}$ is favored by most teams) [13••], and the pump is placed in the labia majora creating a subcutaneous space from the abdominal incision. 


\section{The Rise of Minimally Invasive Surgical Approaches}

The challenge of AUS implantation in females lies in the dissection of the bladder neck. As stated by Scott, one of the fathers of AUS, this surgery is difficult because there is no natural plane between the urethra and vagina [39] and the bladder neck is located deep in the pelvis. The open approach has been predominant for AUS implantation in female patients for decades, yielding deceiving perioperative outcomes in most series with up to $43.8 \%$ of intraoperative bladder neck injury, up to $25 \%$ of intraoperative vaginal injury, and up to $45.3 \%$ rate of explantation [13••]. This relatively high morbidity has led surgeons to explore other approaches aiming to minimize the technical difficulty of AUS implantation. In the late 2000s, laparoscopic AUS implantation in female patients was described with encouraging outcomes in experienced hands [40,41]. More recently, several series have reported the use of a robotic approach for female AUS implantation, which may combine minimally invasiveness and lower technical complexity compared to the laparoscopic route, thanks to the enhanced dexterity with the endowrist technology allowing multiple dimensions mobility of the instruments, the magnified 3D image, the physiologic tremor filtering, and motion scaling of the surgical robot $[15 \bullet \bullet, 42 \bullet, 43 \bullet$, $44-47,48 \cdot \bullet$. In addition to technically facilitating the implantation per se, laparoscopic and even more robotic approaches offer significant educational advantages, thanks to the perfect vision trainees can get and tools such as dual console and simulators. The studies reporting on robotic AUS implantation in female patients are presented in Table 3 . In a preliminary series of six cases, Fournier et al. reported promising outcomes with no explantation/erosion and $83.3 \%$ of patients fully continent post-operatively $[42 \bullet \bullet]$. The technique used largely duplicated the surgical steps of the traditional open technique, using the same "anterior" robotic technique, with a paramount role of the assistant finger pushing the vaginal fornix to expose the vesicovaginal plane allowing direct vision throughout the bladder neck dissection (Fig. 1), Peyronnet et al. later reported their eight first robotic cases and observed a significantly decreased postoperative complications rate compared to their open cohort $(25 \%$ vs. $75 \%$; $p=$ 0.02 ) with a reduced length of hospital stay (3.8 vs. 9.3 days; $p=0.09$ ) [43•]. The excellent outcomes of this technique were further confirmed in a multicenter series of 49 cases with a minimum 12 months follow-up. In this complex patients' population with $85.7 \%$ having a history of previous antiincontinence surgery, the authors reported only one explantation $(2 \%)$ with $81.6 \%$ of patients fully continent after a median follow-up of 18.5 months [15••]. An international multicenter experience of 123 patients implanted in 14 institutions from four European countries using this technique was to be presented as a conference abstract this year, confirming these findings with only four explantations for erosion after a median follow-up of 13 months (3.3\%) [45]. A Canadian team reported a first case using a similar "anterior" robotic technique in 2019 [47]. Using a slightly different technique, without the help of the assistant's finger and with the cuff placed more distally towards the mid urethra, Biardeau et al. reported 9 cases with less favorable outcomes, especially $22.2 \%$ of erosions, highlighting the need of standardized surgical steps in addition to the robotic approach to decrease female AUS

Table 3 Series of robot-assisted artificial urinary sphincter implantation in women

\begin{tabular}{|c|c|c|c|c|c|c|c|c|c|}
\hline Study & $\begin{array}{l}\text { Number } \\
\text { of } \\
\text { patients }\end{array}$ & $\begin{array}{l}\text { Bladder } \\
\text { neck injury } \\
(\%)\end{array}$ & $\begin{array}{l}\text { Vaginal } \\
\text { injury } \\
(\%)\end{array}$ & $\begin{array}{l}\text { Mean length } \\
\text { of stay } \\
\text { (days) }\end{array}$ & $\begin{array}{l}\text { Post-operative } \\
\text { complications } \\
(\%)\end{array}$ & $\begin{array}{l}\text { Major } \\
(\text { Clavien } \geq 3) \\
\text { complications }(\%)\end{array}$ & $\begin{array}{l}\text { Mean } \\
\text { follow-up } \\
\text { (months) }\end{array}$ & $\begin{array}{l}\text { Explantation* } \\
(\%)\end{array}$ & $\begin{array}{l}\text { Revision* } \\
(\%)\end{array}$ \\
\hline $\begin{array}{l}\text { Fournier G } \\
2014[42 \bullet \bullet]\end{array}$ & 6 & $0 \%$ & $0 \%$ & 6 & $16.7 \%$ & $0 \%$ & 14.3 & $0 \%$ & $0 \%$ \\
\hline $\begin{array}{l}\text { Biardeau X } \\
2015 \text { [44] }\end{array}$ & $9^{1}$ & $22.2 \%$ & $22.2 \%$ & 4.9 & $33.3 \%$ & $22.2 \%$ & 18.9 & $22.2 \%$ & $0 \%$ \\
\hline $\begin{array}{l}\text { Peyronnet B } \\
2016 \text { [43•] }\end{array}$ & 8 & $25 \%$ & $12.5 \%$ & 3.5 & $25 \%$ & $12.5 \%$ & 5 & $12.5 \%$ & $0 \%$ \\
\hline $\begin{array}{l}\text { Peyronnet B } \\
2019[15 \bullet \bullet\end{array}$ & 49 & $10.2 \%$ & $6.1 \%$ & 4 & $18.3 \%$ & $4.1 \%$ & 18.5 & $2 \%$ & $6.1 \%$ \\
\hline $\begin{array}{l}\text { Kourbanhoussen } \\
\text { K } \\
2019[46]\end{array}$ & 10 & $40 \%$ & $0 \%$ & 4.1 & $20 \%$ & $10 \%$ & 22 & $0 \%$ & $20 \%$ \\
\hline $\begin{array}{l}\text { Gondran- } \\
\text { Tellier } 2020 \\
{[47]}\end{array}$ & 8 & $0 \%$ & $0 \%$ & NR & $37.5 \%$ & $0 \%$ & 12 & $0 \%$ & $0 \%$ \\
\hline $\begin{array}{l}\text { Peyronnet B } \\
2020 \text { [45] }\end{array}$ & 123 & $9.8 \%$ & $6.5 \%$ & 3.5 & $18 \%$ & $3.3 \%$ & 13 & $4.1 \%$ & $5.5 \%$ \\
\hline
\end{tabular}

${ }^{1}$ Only AUS implantations are presented (the two revisions were excluded) 
implantation surgical morbidity [44]. More recently, Gondran-Tellier et al. described an alternative robotic technique of AUS implantation in female patients, with a posterior approach of the bladder neck involving a full dissection of the vesico-vaginal plane starting at the vaginal dome with the aim of facilitating the vision of the posterior dissection of the bladder neck at the cost of a more extensive dissection [48••]. They reported no intraoperative bladder neck or vaginal injury and no erosion after a median follow-up of 12 months [48••]. A Spanish team recently described the use of the same "posterior" technique with a laparoscopic approach [49]. Interestingly, an association between the development of these minimally invasive implantation techniques and an increase in the use of female AUS has been noted in France $(+28.9 \%$ from 205 to 2017) suggesting that the technical facilitation of AUS implantation, thanks to these newer approaches, may favor the adoption of female AUS by urologists [26••].

\section{Existing Evidence}

Although female AUS implantation has been described almost five decades ago, the evidence supporting its use is relatively limited $[13 \bullet \cdot]$. Especially, no randomized controlled trial (RCT) nor prospective series on AUS implantation in female patients has been published so far [13••]. In the current evidence-based medicine era, this may have hindered its adoption by the urological community [13••]. However, this may clearly not be regarded as the only factor explaining this relatively limited use given that there is a similar lack of high level of evidence studies supporting the use of male AUS (only one underpowered poorly designed RCT) [50, 51]. Under the auspices of the ICS, an international group of experts recently performed a systematic review of the female AUS literature following the PRISMA statement and Cochrane Handbook recommendations [13••]. They found 17 case series, mostly retrospective, reporting on 6 to 344 female AUS patients. The vast majority of patients had undergone at least one anti-incontinence surgical procedure prior to AUS implantation $(69.1 \%$ to $100 \%)$. Neurogenic SUI accounted for $0 \%$ to $50 \%$ of indications [13 ••]. One study reported on vaginal AUS implantation, 11 on open AUS implantation, two on laparoscopic AUS implantation, two on robot-assisted AUS implantation, and one compared open and robot-assisted implantations. The intraoperative bladder neck injury rate ranged from $5.8 \%$ to $43.8 \%$, from 0 to $16.7 \%$, and from 0 to $25 \%$ in open, laparoscopic, and robot-assisted series, respectively. The intraoperative vaginal injury rates ranged from 0 to $25 \%$ with the open approach, from $2 \%$ to $16.7 \%$ with the laparoscopic approach and from $0 \%$ to $25 \%$ with the robot-assisted approach. Interestingly, among open series, the two largest studies reported the lowest rates of intraoperative bladder neck and/or vaginal injury [13••]. The mean length of stay was rarely reported, but when it was, it tended to be shorter in the laparoscopic ( 2 to 7 days) and robot-assisted (3.5 to 6 days) cohorts than in the open cohorts (9.3 to 14.1 days). The postoperative complications rates varied widely and ranged from $16.7 \%$ to $33.3 \%$ in robotic series and from $4.1 \%$ to $75 \%$ in open series. After mean follow-up periods ranging from 5 to 204 months, the complete, social, and improved continence rates ranged from $61.1 \%$ to $100 \%$, from $71 \%$ to $100 \%$ and from $81.3 \%$ to $100 \%$, respectively.

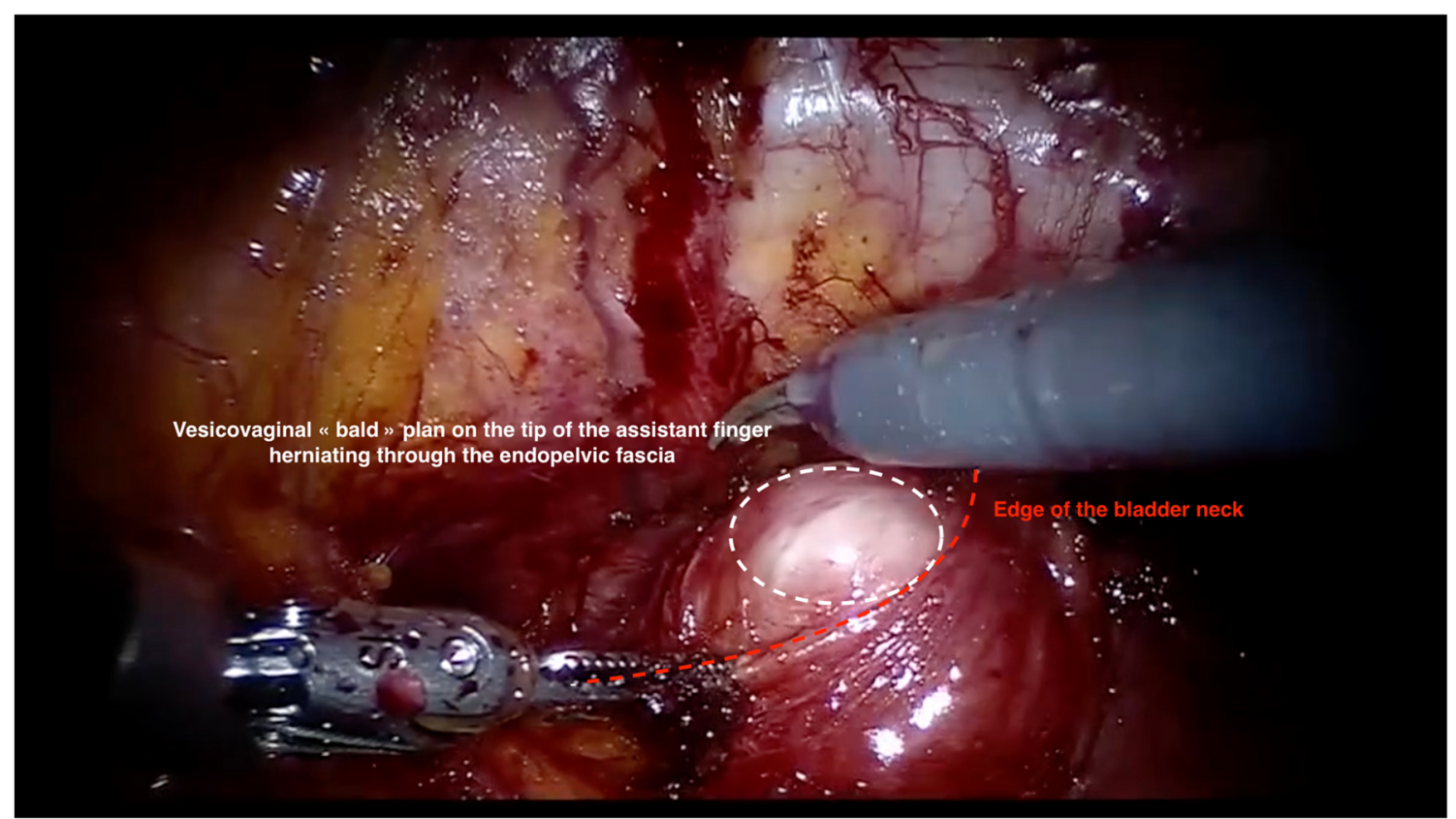

Fig. 1 Assistant finger pushing into the right vaginal fornix upward and laterally towards the ipsilateral shoulder therefore creating a hernia into the endopelvic fascia and exposing progressively the vesicovaginal plane 
The rates of explantation, erosion, and mechanical failure varied from $0 \%$ to $45.3 \%, 0 \%$ to $22.2 \%$, and $0 \%$ to $44.1 \%$, respectively [13••]. Seven series, all reporting on open AUS implantations, had a mean follow-up over 5 years (range: 72.3 to 204 months) [13••]. At the latest follow-up in these series, $61.1 \%$ to $85.6 \%$ of patients reported being fully continent $[13 \bullet \bullet]$.

\section{Perspectives}

AMS-800 AUS is the only mechanical device that can mimic the function of biological urinary sphincter by increasing the outlet resistance during the storage phase while maintaining low outlet resistance during the voiding phase when the cuff is opened. While it has proven to be safe and effective, AMS800 AUS is not without limitations. One of the most significant is the need to activate the pump to void which can be an important barrier to AUS use in female patients with up to $14.9 \%$ failing to manipulate the pump [13••]. A handful of electromechanical artificial sphincters have been developed over the past decade, but none has gone from bench to bedside [52-54]. The main advantages of electromechanical AUS are that they would be remotely controlled, allowing the labia majora pump to be omitted, and that they may allow to adjustment the pressure exerted on the urethra, hypothetically reducing the risk of erosion and revision due to damage to the bladder neck tissue. Several teams and industrial companies are currently working on electromechanical AUS prototypes which should be used in clinical research studies in the near future.

With the steadily increasing popularity of robotic approaches for AUS implantation in female patients, technological advances in the field of robotic surgery may also be an added value to female AUS developments especially with systems such as the Da Vinci Single port platform which may facilitate even more AUS implantation owing to the improved ergonomics [55].

Finally, lack of high level of evidence studies is a drawback of female AUS use which should be overcome in upcoming years with two large prospective studies currently ongoing and recruiting: the SUACT trial (clinicaltrials.gov identifier: NCT02490917), a RCT comparing adjustable continence therapy periurethral balloons to AUS in female patients with SUI due to ISD, and the VENUS study, a prospective cohort study on female AUS involving 25 centers throughout Europe and conducted by the EAU Research Foundation.

\section{Conclusion}

Owing to its excellent functional outcomes, long history, and unique potential to restore continence while maintaining low outlet resistance during the voiding phase, AMS-800 AUS can be a valuable option to treat female patients with SUI due to ISD. While its use has been restricted to some countries and a few high-volume centers, it has started spreading again over the past few years, thanks to the rise of minimally invasive approaches which facilitate its implantation, and this is yielding promising outcomes. High level of evidence data from trials which are underway, along with developments in robotic surgery and technological refinements of the device, may well, almost 50 years after its introduction, give the AUS momentum as a major contributor in the female SUI armamentarium.

\section{Compliance with Ethical Standards}

Conflicts of Interest Dr. Peyronnet is a consultant for Allergan, Medtronic, Astellas, Pierre Fabre and reports personal fees from Boston Scientific, outside the submitted work.

Dr. Thiruchelvam reports personal fees from Boston Scientific, during the conduct of the study; personal fees from Teleflex, personal fees from Coloplast, personal fees from Galvani, outside the submitted work.

Dr. Greenwell reports personal fees from Boston scientific, other from Astellas, other from Axonics, other from Contura, other from ferring, other from June Medical, other from Laborie, other from Medtronic, outside the submitted work.

Dr. Van Koeveringe reports personal fees from Boston Scientific, outside the submitted work.

Dr. Gray reports personal fees from Boston scientific, grants from Bioness, personal fees from Axonics, from Contura, outside the submitted work.

Dr. Fournier reports personal fees from Boston Scientific, outside the submitted work.

Dr. Capon reports personal fees from Boston Scientific, outside the submitted work.

Dr. Van der Aa reports personal fees from Boston Scientific, other from Cousin, personal fees from Promedon, outside the submitted work.

Dr. López-Fando reports personal fees from Astellas Pharma SA, personal fees from Neomedic, personal fees from Boston Scientific, personal fees from Wellspect, personal fees from Coloplast, outside the submitted work.

Dr. Khavari and Dr. Gilleran each have nothing to disclose.

Human and Animal Rights and Informed Consent This article does not contain any studies with human or animal subjects performed by any of the authors.

\section{References}

Papers of particular interest, published recently, have been highlighted as:

- Of importance

•- Of major importance

1. Osman NI, Li Marzi V, Cornu JN, Drake MJ. Evaluation and classification of stress urinary incontinence: current concepts and future directions. Eur Urol Focus. 2016;2(3):238-44.

2. Gil KM, Somerville AM, Cichowski S, Savitski JL. Distress and quality of life characteristics associated with seeking surgical 
treatment for stress urinary incontinence. Health Qual Life Outcomes. 2009;7:8.

3. Tennstedt SL, Fitzgerald MP, Nager CW, Xu Y, Zimmern P, Kraus $\mathrm{S}$, et al. Quality of life in women with stress urinary incontinence. Int Urogynecol J Pelvic Floor Dysfunct. 2007;18(5):543-9.

4.- Sussman RD, Syan R, Brucker BM. Guidelines of the Guidelines: Urinary Incontinence in Women. BJU Int. 2019; in press:638-55. https://doi.org/10.1111/bju.14927. Overview of current national and international guidelines on urinary incontinence in women.

5. Lee E, Nitti VW, Brucker BM. Midurethral slings for all stress incontinence: a urology perspective. Urol Clin North Am. 2012;39(3):299-310.

6. Hillary CJ, Osman N, Chapple C. Considerations in the modern management of stress urinary incontinence resulting from intrinsic sphincter deficiency. World J Urol. 2015;33(9):1251-6.

7. Nadeau G, Herschorn S. Management of Recurrent Stress Incontinence Following a sling. Curr Urol Rep. 2014;15(8):427.

8. Giarenis I, Thiagamoorthy G, Zacchè M, Robinson D, Cardozo L. Management of recurrent stress urinary incontinence after failed midurethral sling: a survey of members of the International Urogynecological Association (IUGA). Int Urogynecol J. 2015;26(9):1285-91.

9. Cour F, Le Normand L, Lapray J-F, et al. Intrinsic sphincter deficiency and female urinary incontinence. Prog Urol. 2015;25(8):437-54.

10. Lee R, Te AE, Kaplan SA, Sandhu JS. Temporal trends in adoption of and indications for the artificial urinary sphincter. J Urol. 2009;181(6):2622-7.

11. Scott FB, Bradley WE, Timm GW. Treatment of urinary incontinence by implantable prosthetic sphincter. Urology. 1973;1(3): $252-9$.

12. Scott FB, Bradley WE, Timm GW. Treatment of urinary incontinence by an implantable prosthetic urinary sphincter. J Urol. 1974;112(1):75-80.

13.• Peyronnet B, O'Connor E, Khavari R, et al. AMS-800 Artificial urinary sphincter in female patients with stress urinary incontinence: A systematic review. Neurourol Urodyn. 2019;38(Suppl 4):S28-41. Recent systematic review on the available evidence on artificial urinary sphincter in female patients conducted under the auspices of the International Continence Society.

14. Chartier-Kastler E, Van Kerrebroeck P, Olianas R, et al. Artificial urinary sphincter (AMS 800) implantation for women with intrinsic sphincter deficiency: a technique for insiders? BJU Int. 2011;107(10):1618-26.

15.• Peyronnet B, Capon G, Belas O, et al. Robot-assisted AMS-800 Artificial Urinary Sphincter Bladder Neck Implantation in Female Patients with Stress Urinary Incontinence. Eur Urol. 2019;75(1): 169-75. Largest series of robotic artificial urinary sphincter implantation published to date reporting on 49 patients from five French institutions with a minimum 1-year follow up with a $2 \%$ explantation rate and $81.6 \%$ of patients fully continent postoperatively.

16. Cox A, Herschorn S, Lee L. Surgical management of female SUI: is there a gold standard? Nat Rev Urol. 2013;10(2):78-89.

17. Haylen BT, Lee JKS, Sivagnanam V, Cross A. What if there were no tapes? Neurourol Urodyn. 2018;37(6):2026-34.

18. Tommaselli GA, Di Carlo C, Formisano C, Fabozzi A, Nappi C. Medium-term and long-term outcomes following placement of midurethral slings for stress urinary incontinence: a systematic review and metaanalysis. Int Urogynecol J. 2015;26(9):1253-68.

19. Khan ZA, Nambiar A, Morley R, Chapple CR, Emery SJ, Lucas MG. Long-term follow-up of a multicentre randomised controlled trial comparing tension-free vaginal tape, xenograft and autologous fascial slings for the treatment of stress urinary incontinence in women. BJU Int. 2015;115(6):968-77.

20. Wlaźlak E, Viereck V, Kociszewski J, Kuszka A, Rautenberg O, Walser C, et al. Role of intrinsic sphincter deficiency with and without urethral hypomobility on the outcome of tape insertion. Neurourol Urodyn. 2017;36(7):1910-6.

21. Lo TS, Pue LB, Tan YL, Wu PY. Risk factors for failure of repeat midurethral sling surgery for recurrent or persistent stress urinary incontinence. Int Urogynecol J. 2016;27(6):923-31.

22. Pirpiris A, Shek KL, Dietz HP. Urethral mobility and urinary incontinence. Ultrasound Obstet Gynecol. 2010;36(4):507-11.

23. Caputo RM, Benson JT. The Q-tip test and urethrovesical junction mobility. Obstet Gynecol. 1993;82(6):892-6.

24. Robinson BL, Geller EJ, Parnell BA, Crane AK, Jannelli ML, Wells EC, et al. Diagnostic accuracy of visual urethral mobility exam versus Q-Tip test: a randomized crossover trial. Am J Obstet Gynecol. 2012;206(6):528.e1-6.

25. Matsushita K, Chughtai BI, Maschino AC, Lee RK, Sandhu JS. International variation in artificial urinary sphincter use. Urology. 2012;80(3):667-72.

26.• Peyronnet B, Hascoet J, Scailteux LM, Gamé X, Cornu JN. The changing face of artificial urinary sphincter use in France: the future is female. Eur Urol Focus. 2018;S2405-4569(18)30404-8. https:// doi.org/10.1016/j.euf.2018.12.005. French epidemiological study conducted on the national claim database (PMSI) demonstrating a $28.9 \%$ increase in the use of artificial sphincter in female patients in France in the two years following the first description of robotic artificial sphincter implantation in female patients.

27. Kraus SR, Lemack GE, Richter HE, Brubaker L, Chai TC, Albo $\mathrm{ME}$, et al. Changes in urodynamic measures two years after Burch colposuspension or autologous sling surgery. Urology. 2011;78(6): 1263-8.

28.• Phé V, Léon P, Granger B, et al. Stress urinary incontinence in female neurological patients: long-term functional outcomes after artificial urinary sphincter (AMS 800) implantation. Neurourol Urodyn. 2017;36(3):764-9. Largest long-term series of female AUS in neurogenic patients demonstrating satisfactory functional outcomes with relatively limited rates of erosion, explantation and revision.

29. Tricard T, Schirmann A, Munier P, Schroeder A, Saussine C. Outcomes of artificial urinary sphincter in female with neurological stress urinary incontinence: a long-term follow-up. World J Urol. 2020;in press. https://doi.org/10.1007/s00345-020-03105-2.

30. Khene ZE, Paret F, Perrouin-Verbe MA, Prudhomme T, Hascoet J, Nedelec M, et al. Artificial Urinary Sphincter in Male Patients with Spina Bifida: Comparison of Perioperative and Functional Outcomes between Bulbar Urethra and Bladder Neck Cuff Placement. J Urol. 2018;199(3):791-7.

31. Bakali E, Johnson E, Buckley BS, Hilton P, Walker B, Tincello DG. Interventions for treating recurrent stress urinary incontinence after failed minimally invasive synthetic midurethral tape surgery in women. Cochrane Database Syst Rev. 2019;9:CD009407.

32. Farag F, Koens M, Sievert KD, De Ridder D, Feitz W, Heesakkers J. Surgical treatment of neurogenic stress urinary incontinence: a systematic review of quality assessment and surgical outcomes. Neurourol Urodyn. 2016;35(1):21-5.

33. Burkhard C, Bosch JL, Cruz F, et al. EAU guidelines on urinary incontinence in adults. 2020. Available online at: https://uroweb. org/guideline/urinary-incontinence/. Accessed 05/10/2020.

34. Gomelsky A, Athanasiou S, Choo MS, Cosson M, Dmochowski $\mathrm{RR}$, Gomes CM, et al. Surgery for urinary incontinence in women: Report from the 6th international consultation on incontinence. Neurourol Urodyn. 2019;38(2):825-37.

35. NICE. Guidance - urinary incontinence and pelvic organ prolapse in women: management: (c) NICE (2019) urinary incontinence and pelvic organ prolapse in women: management. BJU Int. 2019;123(5):777-803.

36.• Costa P, Poinas G, Ben Naoum K, et al. Long-term results of artificial urinary sphincter for women with type III stress urinary 
incontinence. Eur Urol. 2013;63(4):753-8. Largest series of female AUS ever published reporting on a 344 patients 20 years' experience from a single expert center (Nimes, France).

37. Kobashi KC, Albo ME, Dmochowski RR, Ginsberg DA, Goldman HB, Gomelsky A, et al. Surgical Treatment of Female Stress Urinary Incontinence: AUA/SUFU Guideline. J Urol. 2017;198(4):875-83.

38. Peyronnet B, Brucker BM. Management of Overactive Bladder Symptoms After Radical Prostatectomy. Curr Urol Rep. 2018;19(12):95.

39. Scott FB. The use of the artificial sphincter in the treatment of urinary incontinence in the female patient. Urol Clin North Am. 1985;12(2):305-15.

40. Mandron E, Bryckaert PE, Papatsoris AG. Laparoscopic artificial urinary sphincter implantation for female genuine stress urinary incontinence: technique and 4 -year experience in 25 patients. BJU Int. 2010;106(8):1194-8.

41. Rouprêt M, Misraï V, Vaessen C, Cardot V, Cour F, Richard F, et al. Laparoscopic approach for artificial urinary sphincter implantation in women with intrinsic sphincter deficiency incontinence: a single-centre preliminary experience. Eur Urol. 2010;57(3):499-504.

42.•• Fournier G, Callerot P, Thoulouzan M, et al. Robotic-assisted laparoscopic implantation of artificial urinary sphincter in women with intrinsic sphincter deficiency incontinence: initial results. Urology. 2014;84(5):1094-8. First preliminary report of robotic AUS implantation in female patient (6 cases).

43. Peyronnet B, Vincendeau S, Tondut L, Bensalah K, Damphousse M, Manunta A. Artificial urinary sphincter implantation in women with stress urinary incontinence: preliminary comparison of robotassisted and open approaches. Int Urogynecol J. 2016;27(3):47581. Single center case series comparing the open and robotic approach (16 vs. 8) with significantly better perioperative outcomes in the robotic group.

44. Biardeau X, Rizk J, Marcelli F, Flamand V. Robot-assisted laparoscopic approach for artificial urinary sphincter implantation in 11 women with urinary stress incontinence: surgical technique and initial experience. Eur Urol. 2015;67(5):937-42.

45. Peyronnet B, Capon G, Belas O, et al. Robot-assisted artificial urinary sphincter implantation in female patients: an international multicenter study. Eur Urol. 2020;19:e604-5.
46. Kourbanhoussen K, Cecchi M, Chevrot A, et al. Laparoscopic robot-assisted artificial urinary sphincter in women: First approach. Prog Urol. 2019;29(7):371-7.

47. Zhao Y, Gray G, St Martin B. Techniques - robotic-assisted laparoscopic implantation of artificial urinary sphincter with concomitant hysterectomy and sacrocolpopexy. Can Urol Assoc J. 2019;13(7):E232-4.

48.• Gondran-Tellier B, Boissier R, Baboudjian M, et al. Robot-assisted implantation of an artificial urinary sphincter, the AMS-800, via a posterior approach to the bladder neck in women with intrinsic sphincter deficiency. BJU Int. 2019;124(6):1077-80. First preliminary report of an alternative "posterior" robotic approach for AUS implantation in female patients.

49. Ruiz-Hernández M, López-Fando L, Gómez de Vicente JM, et al. A new approach to laparoscopic implantation of the artificial urinary sphincter: Vesicovaginal approach to the bladder neck. Actas Urol Esp. 2019;43(1):44-50.

50. Kretschmer A, Hübner W, Sandhu JS, Bauer RM. Evaluation and management of postprostatectomy incontinence: a systematic review of current literature. Eur Urol Focus. 2016;2(3):245-59.

51. Imamoglu MA, Tuygun $\mathrm{C}$, Bakirtas $\mathrm{H}$, Yiğitbasi $\mathrm{O}$, Kiper A. The comparison of artificial urinary sphincter implantation and endourethral macroplastique injection for the treatment of postprostatectomy incontinence. Eur Urol. 2005;47(2):209-13.

52. Valerio M, Jichlinski P, Dahlem R, Tozzi P, Mundy AR. Experimental evaluation of an electromechanical artificial urinary sphincter in an animal model. BJU Int. 2013;112(4):E337-43.

53. Biardeau X, Hached S, Loutochin O, Campeau L, Sawan M, Corcos J. Montreal electronic artificial urinary sphincters: Our futuristic alternatives to the AMS800 ${ }^{\mathrm{TM}}$. Can Urol Assoc J. 2017;11(10):E396-404.

54. Ludwig TA, Reiss P, Wieland M, Becker A, Fisch M, Chun FK, et al. The ARTUS device: the first feasibility study in human cadavers. Can J Urol. 2015;22(6):8100-4.

55. Gettman M, Rivera M. Innovations in robotic surgery. Curr Opin Urol. 2016;26(3):271-6.

Publisher's Note Springer Nature remains neutral with regard to jurisdictional claims in published maps and institutional affiliations. 